\title{
Solusi Persamaan Transport dengan Menggunakan Metode Dekomposisi Adomian Laplace
}

\author{
Wahidah Sanusi ${ }^{1}$, Syafruddin Side ${ }^{1}$, dan Beby Fitriani ${ }^{1, \text { a) }}$ \\ ${ }^{1}$ Jurusan Matematika FMIPA Universitas Negeri Makassar, 90224 \\ a)bebyfitriani2897@gmail.com
}

Abstrak. Penelitian ini mengkaji terbentuknya persamaan Transport dan menerapkan metode Dekomposisi Adomian Laplace dalam menentukan solusi persamaan Transport. Bentuk umum persamaan Transport yaitu:

$$
\frac{\partial u}{\partial t}+c \frac{\partial u}{\partial x}=0
$$

Penyelesaian persamaan Transport dengan metode Dekomposisi Adomian Laplace dilakukan dengan cara menggunakan tranformasi Laplace, mensubstitusi nilai awal, menyatakan solusi dalam bentuk deret tak hingga dan menggunakan invers transformasi laplace. Berdasarkan hasil perhitungan, metode dekomposisi Adomian Laplace dapat menghampiri penyelesaian persamaan diferensial biasa nonlinear.

Kata Kunci: Metode Dekomposisi Adomian Laplace, Persamaan Diferensial Parsial, Persamaan Transport.

Abstract.This research is studying the established of Tranport equation and applying Adomian Laplace Decompotion method in determining Transport equation solution. The general type of Laplace equation is:

$$
\frac{\partial u}{\partial t}+c \frac{\partial u}{\partial x}=0
$$

Finishing of Transport equation by Adomian Laplace Decompotion method is conducted by using Laplace transform, substituting the initial value, declaring the solution in the form of an infinite series and using the laplace transform inverse. Based on the results of calculations, the decomposition method of Adomian Laplace can approach the completion of nonlinear ordinary differential equations.

Keywords: Adomian Laplace Decomposition Method, Partial Differential Equations, Transport Equations.

\section{PENDAHULUAN}

Matematika adalah sebagai sumber dari ilmu yang lain dan pada perkembangannya tidak tergantung pada ilmu lain. Dengan kata lain, banyak ilmu-ilmu yang penemuan dan pengembangannya bergantung dari matematika. Sebagai contoh: banyak teori-teori dan cabang-cabang dari fisika dan kimia yang ditemukan dan dikembangkan melalui konsep kalkulus. Selain itu, matematika biasanya digunakan manusia untuk memecahkan masalahnya dalam kehidupan sehari-hari.

Salah satu diantara model matematika yang cukup penting adalah Persamaan Diferensial (PD). Persamaan diferensial adalah persamaan yang melibatkan variabel-variabel tak bebas dan derivatifderivatifnya terhadap variabel- variabel bebas. Persamaan diferensial diklasifikasikan dalam dua kelas yaitu biasa dan parsial. Persamaan diferensial biasa adalah persamaan yang hanya memuat turunan yang terdiri dari satu atau lebih variabel tak bebas dengan satu variabel bebas, sedangkan persamaan diferensial parsial adalah persamaan yang memuat turunan parsial satu atau lebih variabel tak bebas terhadap dua atau lebih variabel bebas (Side, 2016).

Dalam pengaplikasiannya yaitu digunakan pada permodelan persamaan transport, gelombang satu dimensi dan konduksi panas. Penyelesaian permasalahan tersebut dapat dilakukan dengan berbagai metode. Persamaan transport merupakan salah satu persamaan gelombang yang menggambarkan mekanisme transportasi suatu substansi yang mengalir dalam fluida dengan arah tertentu (aliran 
fluida). Dari pengertian tersebut akan didapatkan suatu persamaan yang diperoleh berdasarkan hukum kekekalan massa yang disebut persamaan transport (Monika, 2018).

Persamaan transport tersebut inilah yang dapat diselesaikan dengan sebuah metode yang dikenalkan oleh George Adomian seorang matematikawan dari Amerika, dimana metode tersebut lebih dikenal dengan Metode Dekomposisi Adomian. Pada metode ini, persamaan diferensial ditulis dalam bentuk persamaan operator. Operator yang digunakan merupakan operator diferensial. Selanjutnya, operator diferensial pada Metode Dekomposisi Adomian diganti dengan operator transformasi Laplace $\mathcal{L}$ dan invers dari operator $\mathcal{L}$ adalah invers transformasi Laplace $L^{-1}$. Selanjutnya, metode ini disebut Metode Dekomposisi Adomian Laplace (Yuni, 2012 ).

Persamaan Transport sebelumnya telah diterapkan (Ipung Setiawan dkk., 2011) dalam artikelnya yang berjudul "Solusi Analitik Persamaan Transport dan Distribusi Anomiak". Persamaan ini dibentuk melalui proses transformasi dari amoniak menjadi nitrit dalam proses nitrifikasi. Selanjutnya, persamaan diferensial parsial yang terbentuk dicari solusinya dengan mengaplikasikan transformasi Laplace. Selain itu, penelitian yang dilakukan oleh (Rabiatul Adawiyah, 2016) menggunakan metode dekomposisi Adomian Laplace untuk menyelesaikan persamaan gelombang kejut (shock wave). Pada penelitian tersebut persamaan shock wave diselesaikan dengan metode Dekomposisi Adomian Laplace agar dapat diperoleh solusinya.

Oleh karena itu, pada artikel ini dibahas mengenai prosedur matematis persamaan Transport serta menerapkan metode Dekomposisi Adomian Laplace dalam menentukan solusi umum persamaan Transport.

\section{Persamaan Diferensial Biasa Linear}

Persamaan diferensial biasa linear memiliki bentuk umum sebagaimana pada persamaan (1).

$$
a_{m}(x) \frac{d^{m} y}{d x^{m}}+a_{m-1}(x) \frac{d^{(m-1)} y}{d x^{(m-1)}}+\cdots+a_{1}(x) \frac{d y}{d x}+a_{0}(x) y=r(x)
$$

dengan dengan $a_{i}(x), i=1,2, \ldots, m$ didefinisikan dan kontinu pada suatu selang $\mathrm{I}$ adalah persamaan diferensial linear.

\section{Persamaan Diferensial Parsial}

Persamaan diferensial parsial adalah persamaan diferensial yang memuat lebih dari satu variabel bebas. Adapun bentuk umum persamaan diferensial parsial linier orde-2 :

$$
A u_{x x}+B u_{x y}+C u_{y y}+D u_{x}+E u_{y}+F u=G
$$

Dimana $A, B, C, D, E, F$, dan $G$ adalah fungsi-fungsi yang bergantung pada $x$ dan $y$.

Terdapat 3 jenis persamaan diferensial parsial linier yang penting, yaitu parabolik, hiperbolik, dan elliptik. Persamaan diferensial parsial orde dua dalam persamaan diatas:

1. Persamaan diferensial parsial dikatakan persamaan hiperbolik jika nilai diskriminan $B^{2}-4 A C>0$

Salah satu contoh persamaan hiperbolik adalah pada persamaan gelombang

$$
\frac{\partial^{2} u}{\partial t^{2}}-c^{2} \frac{\partial^{2} u}{\partial x^{2}}=0
$$

2. Persamaan diferensial parsial dikatakan persamaan parabolik jika nilai diskriminan $B^{2}-4 A C=0$

Salah satu contoh persamaan parabolik adalah pada persamaan difusi

$$
\frac{\partial u}{\partial t}-c \frac{\partial^{2} u}{\partial x^{2}}=0
$$

3. Persamaan diferensial parsial dikatakan persamaan eliptik jika nilai diskriminan $B^{2}-$ $4 A C<0$ 
Salah satu contoh persamaan eliptik adalah pada persamaan laplace

(Ioninnis P Stavroulakis, 2004)

$$
\frac{\partial^{2} u}{\partial x^{2}}+\frac{\partial^{2} u}{\partial y^{2}}=0
$$

\section{Masalah Nilai Awal}

Dalam kebanyakan permasalahan, penyelesaian unik bagi satu masalah yang diberikan yang kemudian disebut satu penyelesaian khusus, adalah diperoleh dari satu penyelesaian umum mengikuti satu syarat awal $y\left(x_{0}\right)=y_{0}$ dengan diberikan nilai-nilai $x_{0}$ dan $y_{0}$ yang digunakan untuk menentukan skalar hasil dari penyelesaian persamaan diferensial tersebut.

Syarat awal adalah syarat yang dikhususkan pada satu titik yang diberikan. Bilangan syarat awal tak bebas pada peringkat persamaan diferensial. Satu persamaan diferensial biasa dengan satu syarat awal disebut masalah nilai awal [MNA]. Jadi, jika secara jelas satu persamaan diferensial biasa diberikan oleh $y^{\prime}=f(x, y)$, maka masalah nilai awal diberikan oleh:

$$
y^{\prime}=f(x, y), y\left(x_{0}\right)=y_{0}
$$

\section{Persamaan Transport}

Persamaan transport merupakan salah satu persamaan gelombang yang menggambarkan mekanisme transportasi suatu substansi yang mengalir dalam fluida dengan arah tertentu (aliran fluida). Persamaan transport dalam meteorologi dan oseanografi fisik, transport mengacu pada gerak substansi atmosfer atau laut, seperti panas, kelembaban, dan salinitas (kadar garam). Penurunan persamaan transport yaitu berdasarkan hukum kekekalan massa.

Bentuk umum persamaan transport adalah:

$$
\frac{\partial u}{\partial t}+c \frac{\partial u}{\partial x}=0
$$

\section{Transformasi Laplace}

Transformasi laplace dapat diterapkan sebagai metode untuk menyelesaikan persamaan diferensial, baik sebagai masalah nilai awal maupun masalah nilai batas. (Wahidah, 2015).

Definisi 1. (Wahidah, 2015)

Misalkan $\mathbf{f}(\mathbf{t})$ suatu fungsi dari $\mathbf{t}$ yang ditentukan untuk $\mathbf{t}>0$. Maka transformasi Laplace dari $\mathbf{f}(\mathbf{t})$, yang dinyatakan oleh $\mathcal{L}\{\mathbf{f}(\mathbf{t})\}$, didefinisikan sebagai,

$$
\mathcal{L}\{\mathbf{f}(\mathbf{t})\}=\mathbf{F}(\mathbf{s})=\int_{0}^{\infty} \mathbf{f}(\mathbf{t}) \mathbf{e}^{-\mathbf{s t}} \mathbf{d t}
$$

Definisi 2. (Wahidah,2015)

Jika transformasi laplace suatu fungsi $\mathrm{f}(\mathrm{t})$ adalah $\mathrm{F}(\mathrm{s})$, yaitu $\mathcal{L}\{\mathbf{f}(\mathbf{t})\}=\mathbf{F}(\mathbf{s})$ maka $\mathbf{f}(\mathbf{t})$ dinamakan invers transformasi Laplace dari $\mathbf{F}(\mathbf{s})$ dan dinotasikan dengan $\mathbf{f}(\mathbf{t})=\mathcal{L}^{-\mathbf{1}}\{\mathbf{F}(\mathbf{s})\}$ dengan $\mathbf{L}^{-\mathbf{1}}$ disebut operator invers Transformasi Laplace.

\section{Metode Dekomposisi Adomian Laplace}

Diberikan persamaan diferensial yang dinotasikan dalam persamaan operator :

$$
\mathbf{L y}+\mathbf{R y}+\mathbf{N y}=\mathbf{G}
$$


Dengan N adalah operator nonlinear dan L adalah operator diferensial linier orde lebih tinggi $\mathrm{R}$ yang diasumsikan dapat dibalik (invertible), $\mathrm{R}$ adalah operator diferensial linear dari orde yang kurang dari L dan G suku nonhomogen.

Persamaan (8) dapat ditulis menjadi

$$
\mathbf{L y}=\mathbf{G}-\mathbf{R y}-\mathbf{N y}
$$

Selanjutnya jika persamaan (9) menggunakan operator $\mathbf{L}^{-\mathbf{1}}$ diperoleh

$$
\mathbf{y}=\mathbf{h}+\mathbf{L}^{-1} \mathbf{G}-\mathbf{L}^{-1} \mathbf{R y}-\mathbf{L}^{-1} \mathbf{N y}
$$

Dengan $\mathrm{h}$ adalah solusi persamaan homogeny $\mathrm{Ly}=0$ dengan nilai awal atau nilai batas yang diketahui. Kemudian Adomian mendefinisikan solusi y sebagai jumlahan deret tak hingga yaitu

$$
\mathbf{y}=\sum_{\mathbf{n}=\mathbf{0}}^{\infty} \mathbf{y}_{\mathbf{n}},
$$

Masalah lebih lanjut adalah pada dekomposisi suku nonlinier Ny, Adomian mendefinisikan sebagai berikut

$$
\mathbf{N}(\mathbf{y})=\sum_{\mathbf{n}=\mathbf{0}}^{\infty} \mathbf{A}_{\mathbf{n}}
$$

dengan

$$
A_{n}=\frac{1}{n !}\left[\frac{d^{n}}{d \lambda^{n}} \mathbf{N} \sum_{k=0}^{\infty} y_{k} \lambda^{k}\right]_{\lambda=0}
$$

Selanjutnya komponen $\mathbf{A}_{\mathbf{n}}$ disebut polinomial Adomian, didefinisikan sebagai:

$\mathbf{A}_{0}=\mathbf{N}\left(\mathbf{y}_{0}\right)$

$\mathbf{A}_{\mathbf{1}}=\mathbf{u}_{\mathbf{1}} \mathbf{N}^{\prime}\left(\mathbf{y}_{\mathbf{0}}\right)$

$A_{2}=\mathbf{u}_{2} \mathbf{N}^{\prime}\left(\mathbf{y}_{0}\right)+\frac{\mathbf{u}_{1}^{2}}{2} \mathbf{N}^{\prime \prime}\left(\mathbf{y}_{0}\right)$

$\mathbf{A}_{3}=\mathbf{u}_{3} \mathbf{N}^{\prime}\left(\mathbf{y}_{0}\right)+\mathbf{u}_{\mathbf{1}} \mathbf{u}_{2} \mathbf{N}^{\prime \prime}\left(\mathbf{y}_{0}\right)+\frac{\mathbf{u}_{1}^{3}}{3 !} \mathbf{N}^{\prime \prime \prime}(\mathbf{y})$

$\vdots$

Selanjutnya menggunakan Persamaan (11) dan (12) diperoleh :

$$
\sum_{\mathbf{n}=\mathbf{0}}^{\infty} \mathbf{y}_{\mathbf{n}}=\mathbf{h}+\mathbf{L}^{-\mathbf{1}} \mathbf{G}-\mathbf{L}^{-\mathbf{1}} \mathbf{R y}-\mathbf{L}^{-\mathbf{1}} \mathbf{N y}
$$

Dengan mensubstitusi Persamaan (12) dan (13) ke Persamaan (14) diperoleh :

$$
\sum_{n=0}^{\infty} \mathbf{y}_{n}=h+L^{-1} G-L^{-1} R \sum_{n=0}^{\infty} y_{n}-L^{-1} \sum_{n=0}^{\infty} A_{n}
$$

Lebih lanjut, Persamaan (14) dapat diuraikan yaitu

$$
\mathbf{y}_{\mathbf{0}}=\mathbf{h}+\mathbf{L}^{-1} \mathbf{G}
$$

Dan

$y_{n}=-L^{-1}\left(R y_{n-1}\right)-L^{-1}\left(A_{n-1}\right), n=1,2,3, \ldots$

Kelebihan dari metode dekomposisi Adomian Laplace yaitu solusi yang diperoleh lebih sederhana dalam bentuk deret tak hingga.(Yuni, 2012) 


\section{METODE PENELITIAN}

Penelitian ini merupakan penelitian kajian teori. Materi yang digunakan terdiri dari buku-buku dan jurnal-jurnal yang membahas tentang persamaan diferensial, persamaan diferensial parsial, transformasi laplace, teori mengenai metode Dekomposisi Adomian Laplace serta teori mengenai persamaan Transport.

\section{HASIL PENELITIAN}

\section{Prosedur matematis persamaan Transport}

Persamaan transport merupakan salah satu persamaan gelombang yang menggambarkan mekanisme transportasi suatu substansi yang mengalir dalam fluida dengan arah tertentu (aliran fluida). Penurunan persamaan transport yaitu berdasarkan hukum kekekalan massa.

Dalam menurunkan persamaan hukum kekakalan massa, notasi yang akan digunakan yaitu $x$ menyatakan variabel jarak, $t$ menyatakan variabel waktu. Sedangkan untuk menyatakan konsentrasi polutan dan kecepatan pada posisi $x$ dan waktu $t$ adalah $u(x, t)$ dan $c(x, t)$.

Terdapat beberapa asumsi yang digunakan untuk menurunkan persamaan hukum kekekalan massa. Pertama, diasumsikan aliran berada dalam dimensi satu dan hanya melibatkan variabel ruang $x$ saja pada waktu $t$. Kedua, diasumsikan aliran tenang tanpa gangguan dari luar dan kecepatan diabaikan. Ketiga, diasumsikan tempat air kedap atau tertutup rapat. Oleh karena itu, karena massa adalah kekal, maka massa hanya akan berubah karena aliran bergerak melewati titik $x_{1}$ dan $x_{2}$. Massa total pelacak kimia pada selang $\left[x_{1}, x_{2}\right]$ pada waktu $t$ dapat dinyatakan dengan:

$$
M=\int_{x_{1}}^{x_{2}} u(x, t) d x
$$

Perubahan massa pada $\left[x_{1}, x_{2}\right]$ diberikan dengan perbedaan fluks pada $\left[x_{1}, x_{2}\right]$. Misal $F_{i}(t)$ adalah posisi pelacak melewati titik $x_{i}$ untuk $i=1,2$. Saat $F_{i}(t)>0$ berarti pelacak mengalir ke kanan. Saat $F_{i}(t)<0$ berarti pelacak mengalir ke kiri, untuk setiap $\left|F_{i}(t)\right|$ dalam satuan gram per detik. Perubahan massa pada $\left[x_{1}, x_{2}\right]$ berubah hanya saat flux melewati $x_{1}$ dan $x_{2}$, diberikan oleh

$$
\frac{d}{d t} \int_{x_{1}}^{x_{2}} u(x, t) d x=F_{1}(t)-F_{2}(t)
$$

Laju aliran yang melalui setiap titik $(x, t)$ yang merupakan hasil kali massa jenis $u(x, t)$ dan kecepatan $c(x, t)$ disebut fluks massa, yaitu:

$$
\text { Fluks massa }=c(x, t) u(x, t)
$$

Disini, kecepatan menggambarkan seberapa cepat partikel yang bergerak melewati titik $x$, dan massa jenis $u$ menggambarkan berapa banyak partikel kimia yang terkandung dalam aliran disetiap $x$. Misalnya $c(x, t)$ adalah fungsi yang diketahui, sehingga persamaan (17) dapat dinyatakan menjadi

$$
\text { Fluks massa }=f(u, x, t)=c(x, t) u
$$

Karena nilai fluks $f(u)$ bergantung pada nilai $u$, maka persamaan (16) dapat ditulis menjadi

$$
\begin{aligned}
\frac{d}{d t} \int_{x_{1}}^{x_{2}} u(x, t) d x & =f\left(u\left(x_{1}, t\right)\right)-f\left(u\left(x_{2}, t\right)\right) \\
& =-\left.f(u(x, t))\right|_{x_{1}} ^{x_{2}}
\end{aligned}
$$


Jika $u$ dan $f$ adalah fungsi yang terdiferensial maka persamaan (19) dapat ditulis menjadi

$$
\frac{d}{d t} \int_{x_{1}}^{x_{2}} u(x, t) d x=-\int_{x_{1}}^{x_{2}} \frac{\partial}{\partial x} f(u(x, t)) d x
$$

Atau

$$
\frac{d}{d t} \int_{x_{1}}^{x_{2}} u(x, t) d x+\int_{x_{1}}^{x_{2}} \frac{\partial}{\partial x} f(u(x, t)) d x=0
$$

Dengan menggunakan sifat integral tentu, persamaan (21) dapat ditulis menjadi

$$
\int_{x_{1}}^{x_{2}}\left[\frac{\partial}{\partial t} u(x, t)+\frac{\partial}{\partial x} f(u(x, t))\right] d x=0
$$

Persamaan (22) menyatakan bahwa nilai integral dari beberapa jumlah selalu mol untuk setiap nilai limit yang bebas dari integral. Satu-satunya fungsi yang integralnya adalah nol untuk setiap interval adalah fungsi nol, sehingga persamaan menjadi

$$
\frac{\partial}{\partial t} u(x, t) d x+\frac{\partial}{\partial x} f(u(x, t)) d x=0
$$

Atau dapat dituliskan menjadi

$$
u_{t}+f(u)_{x}=0
$$

Persamaan (24) disebut persamaan hukum kekekalan massa.

Dalam proses adveksi, diandaikan sebuah aliran yang terbatas mengalir dengan kecepatan aliran konstan, seperti diilustrasikan pada (Gambar 1).

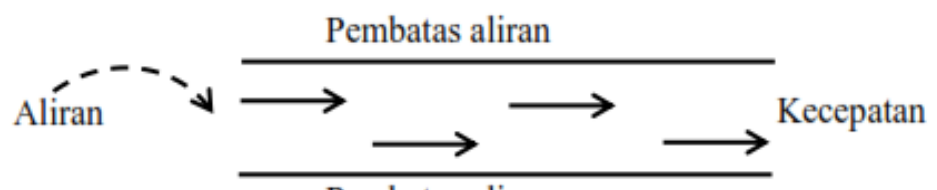

Pembatas aliran

Sumbu- $x$

GAMBAR 1. Aliran sempit mengalir dengan kecepatan konstan

Andaikan terdapat sebuah polutan dan aliran dan polutan tersebut terbawa ke hilir tanpa adanya proses difusi sedikitpun. Berarti, kecepatan $c(x, t)$ adalah konstan. Fluks massa pada persamaan (17) dapat ditulis menjadi:

$$
\text { Fluks massa }=f(u)=c(u)
$$

Dari persamaan (24) diperoleh

$$
u_{t}+(c u)_{x}=0
$$

Persamaan (26) disebut persamaan transport.

\section{Solusi Persamaan Transport dengan Metode Dekomposisi Adomian Laplace}

Dari hasil pemodelan persamaan transport dapat ditulis sebagai :

$$
u_{t}+c u_{x}=0 \text { atau } \frac{\partial u}{\partial t}+c \frac{\partial u}{\partial x}=0
$$

Dengan nilai awal pada persamaan transport dapat ditulis sebagai :

$$
u(x, 0)=f(x)
$$


Dalam menentukan solusi dari persamaan (27) di atas, digunakan langkah-langkah berikut :

Menggunakan Transformasi Laplace pada persamaan (27)

1. Transformasi Laplace dari turunan pertama adalah $\mathcal{L}\left\{\frac{\partial u}{\partial t}\right\}=\int_{0}^{\infty} e^{-s t} \frac{\partial u}{\partial t} d t$

$$
\begin{aligned}
\mathcal{L}\left\{\frac{\partial u}{\partial t}\right\} & =\int_{0}^{\infty} e^{-s t} \frac{\partial u}{\partial t} d t \\
& =\lim _{P \rightarrow \infty} \int_{0}^{P} e^{-s t} \frac{\partial u}{\partial t} d t \\
& =\lim _{P \rightarrow \infty}\left\{\left.e^{-s t} u(x, t)\right|_{0} ^{P}-\int_{0}^{P}(-s) e^{-s t} u(x, t) d t\right\} \\
& =\lim _{P \rightarrow \infty}\left\{\left.e^{-s t} u(x, t)\right|_{0} ^{P}+s \int_{0}^{P} e^{-s t} u(x, t) d t\right\} \\
& =\lim _{P \rightarrow \infty}\left\{e^{-s P} u(x, P)-e^{-s 0} u(x, 0)+s \int_{0}^{P} e^{-s t} u(x, t) d t\right\} \\
& =\lim _{P \rightarrow \infty} e^{-s P} u(x, P)-\lim _{P \rightarrow \infty} e^{-s 0} u(x, 0)+\lim _{P \rightarrow \infty} s \int_{0}^{P} e^{-s t} u(x, t) d t \\
& =0-u(x, 0)+s \int_{0}^{\infty} e^{-s t} u(x, t) d t \\
& =s \int_{0}^{\infty} e^{-s t} u(x, t) d t-u(x, 0) \\
& =s u(x, s)-u(x, 0)
\end{aligned}
$$

Dari uraian diatas, maka Transformasi Laplace dari turunan pertama sebuah fungsi adalah

$$
\mathcal{L}\left\{\frac{\partial u}{\partial t}\right\}=s u(x, s)-u(x, 0)
$$

Untuk Transformasi Laplace pada ruas kanan persamaan (27) digunakan aturan Leibnitz , sehingga diperoleh :

$$
\begin{aligned}
\mathcal{L}\left\{\frac{\partial u}{\partial x}\right\} & =\int_{0}^{\infty} e^{-s t} \frac{\partial u}{\partial x} d t \\
& =\frac{d}{d x} \int_{0}^{\infty} e^{-s t} u d t \\
& =\frac{d(u(x, s))}{d x}
\end{aligned}
$$

Sehingga, $\mathcal{L}\left\{\frac{\partial u}{\partial x}\right\}=\frac{d(u(x, s))}{d x}$

Maka diperoleh transformasi Laplace dari persamaan (27)

$\mathcal{L}\left\{\frac{\partial u}{\partial t}\right\}+c \mathcal{L}\left\{\frac{\partial u}{\partial x}\right\}=0$

$s u(x, s)-u(x, 0)+c \frac{d(u(x, s))}{d x}=0$ 
2. Substitusi nilai awal

Selanjutnya substitusi nilai $u(x, 0)=f(x)$ pada persamaan (29) :

$$
\begin{aligned}
& s u(x, s)-f(x)=-c\left(\frac{d(u(x, s))}{d x}\right) \\
& s u(x, s)=f(x)-c\left(\frac{d(u(x, s))}{d x}\right) \\
& u(x, s)=\frac{f(x)}{s}-\frac{c}{s}\left(\frac{d(u(x, s))}{d x}\right)
\end{aligned}
$$

3. Menyatakan solusi dalam bentuk deret tak hingga $u=\sum_{n=0}^{\infty} u_{n}$

Metode Dekomposisi Adomian mendefinisikan solusi dalam bentuk deret tak hingga, yaitu $u=\sum_{n=0}^{\infty} u_{n}$ dengan $u_{n}$ dihitung secara rekursif.

Hasil yang diperoleh pada persamaan (30) dinyatakan dalam solusi bentuk deret tak hingga $u=\sum_{n=0}^{\infty} u_{n}$.

$u(x, s)=\sum_{n=0}^{\infty} u_{n}(x, s)=\frac{f(x)}{s}-\frac{c}{s}\left(\frac{d}{d x}\left(\sum_{n=0}^{\infty} u_{n}(x, s)\right)\right)$

Diperoleh,

$$
\begin{aligned}
& u_{0}(x, s)=\frac{f(x)}{s} \\
& u_{1}(x, s)=-\frac{c}{s}\left(\frac{d}{d x}\left(\frac{f(x)}{s}\right)\right) \\
& u_{2}(x, s)=\frac{c^{2}}{s^{2}}\left(\frac{d^{2}}{d x^{2}}\left(\frac{f(x)}{s}\right)\right) \\
& u_{3}(x, s)=-\frac{c^{3}}{s^{3}}\left(\frac{d^{3}}{d x^{3}}\left(\frac{f(x)}{s}\right)\right) \\
& u_{4}(x, s)=\frac{c^{4}}{s^{4}}\left(\frac{d^{4}}{d x^{4}}\left(\frac{f(x)}{s}\right)\right) \\
& \vdots \\
& u_{n+1}(x, s)=(-1)^{n+1} \frac{c^{(n+1)}}{s^{(n+1)}}\left(\frac{d^{(n+1)}}{d x^{(n+1)}} u_{0}(x, s)\right) \quad, n \geq 0
\end{aligned}
$$

Sehingga,

$$
\begin{array}{r}
\sum_{n=0}^{\infty} u_{n}(x, s)=\frac{f(x)}{s}-\frac{c}{s}\left(\frac{d}{d x}\left(\frac{f(x)}{s}\right)\right)+\frac{c^{2}}{s^{2}}\left(\frac{d^{2}}{d x^{2}}\left(\frac{f(x)}{s}\right)\right)-\frac{c^{3}}{s^{3}}\left(\frac{d^{3}}{d x^{3}}\left(\frac{f(x)}{s}\right)\right) \\
+\frac{c^{4}}{s^{4}}\left(\frac{d^{4}}{d x^{4}}\left(\frac{f(x)}{s}\right)\right)+\cdots+(-1)^{n+1} \frac{c^{(n+1)}}{s^{(n+1)}}\left(\frac{d^{(n+1)}}{d x^{(n+1)}} u_{0}(x, s)\right)
\end{array}
$$


Yang menghasilkan

$$
\begin{aligned}
u(x, s)= & \frac{f(x)}{s}-\frac{c}{s}\left(\frac{d}{d x}\left(\frac{f(x)}{s}\right)\right)+\frac{c^{2}}{s^{2}}\left(\frac{d^{2}}{d x^{2}}\left(\frac{f(x)}{s}\right)\right)-\frac{c^{3}}{s^{3}}\left(\frac{d^{3}}{d x^{3}}\left(\frac{f(x)}{s}\right)\right)+\frac{c^{4}}{s^{4}}\left(\frac{d^{4}}{d x^{4}}\left(\frac{f(x)}{s}\right)\right)+\cdots+ \\
& (-1)^{n+1} \frac{c^{(n+1)}}{s^{(n+1)}}\left(\frac{d^{(n+1)}}{d x^{(n+1)}} u_{0}(x, s)\right)
\end{aligned}
$$

4. Menggunakan invers Transformasi Laplace

Berdasarkan langkah 3 telah diperoleh, $u(x, s)$ seperti pada persamaan (32).

Selanjutnya untuk memperoleh $u(x, t)$ digunakan invers transformasi Laplace

$$
\begin{aligned}
& u_{0}(x, t)=\mathcal{L}^{-1}\left\{\left(\frac{f(x)}{s}\right)\right\}=f(x) \\
& u_{1}(x, t)=\mathcal{L}^{-1}\left\{-\frac{c}{s}\left(\frac{d}{d x}\left(\frac{f(x)}{s}\right)\right)\right\}=-c \frac{t}{1 !} \frac{\partial}{\partial x} u_{0} \\
& u_{2}(x, t)=\mathcal{L}^{-1}\left\{\frac{c^{2}}{s^{2}}\left(\frac{d^{2}}{d x^{2}}\left(\frac{f(x)}{s}\right)\right)\right\}=c^{2} \frac{t^{2}}{2 !} \frac{\partial^{2}}{\partial x^{2}} u_{0} \\
& u_{3}(x, t)=-c^{3} \frac{t^{3}}{3 !} \frac{\partial^{3}}{\partial x^{3}} u_{0} \\
& u_{4}(x, t)=c^{4} \frac{t^{4}}{4 !} \frac{\partial^{4}}{\partial x^{4}} u_{0} \quad, n \geq 0 \\
& \vdots \\
& u_{n+1}(x, t)=(-1)^{n+1} c^{n+1} \mathcal{L}^{-1}\left\{\frac{1}{s^{(n+1)}}\left(\frac{d^{(n+1)}}{d x^{(n+1)}}\left(\frac{f(x)}{s}\right)\right)\right\} \\
& =(-1)^{n+1} c^{n+1} \frac{t^{n+1}}{(n+1) !} \frac{\partial^{(n+1)}}{\partial x^{(n+1)}} u_{0} \quad, n
\end{aligned}
$$

Jadi , solusi umum persamaan transport adalah

$$
\begin{gathered}
u(x, t)=f(x)-c \frac{t}{1 !} \frac{\partial}{\partial x} u_{0}+c^{2} \frac{t^{2}}{2 !} \frac{\partial^{2}}{\partial x^{2}} u_{0}-c^{3} \frac{t^{3}}{3 !} \frac{\partial^{3}}{\partial x^{3}} u_{0}+c^{4} \frac{t^{4}}{4 !} \frac{\partial^{4}}{\partial x^{4}} u_{0}+ \\
\ldots+(-1)^{n+1} c^{n+1} \frac{t^{n+1}}{(n+1) !} \frac{\partial^{(n+1)}}{\partial x^{(n+1)}} u_{0}
\end{gathered}
$$

\section{PEMBAHASAN}

Penelitian sebelumnya tentang persamaan Transport dan metode Transformasi Laplace, telah dilakukan oleh Ipung dkk (2010). Pada penelitian Ipung, persamaan Transport dan distribusi anomiak diselesaikan dengan metode Transformasi Laplace. Hasil penelitiannya berupa solusi analitik yang serupa dengan fungsi error komplementer. Sedangkan pada penelitian "Solusi Persamaan Transport dengan Metode Dekomposisi Adomian Laplace" persamaan Transport diselesaikan dengan metode Dekomposisi Adomian Laplace. Hasil penelitiannya menunjukkan hal yang berbeda, karena pada penelitian ini diperoleh solusi analitik dari persamaan Transport. 
Penelitian Wartono (2013) \& Rabiatul (2016) dalam penelitiannya metode Dekomposisi Adomian Laplace diterapkan pada persamaan Riccati dan persamaan gelombang kejut (Shockwave) , sedangkan pada penelitian "Solusi Persamaan Transport dengan Metode Dekomposisi Adomian Laplace" ini, peneliti menerapkan metode Dekomposisi Adomian Laplace pada persamaan Transport. Hasil penelitian keduanya menunjukkan hal yang berbeda, Karena penerapan metode ini diselesaikan pada persamaan yang berbeda.

Dengan demikian hasil dari penelitian ini memperoleh solusi umum persamaan Transport dengan Metode Dekomposisi Adomian Laplace yang merupakan solusi analitik. Dari hasil penelitian, dapat diliat bahwa solusi dari metode ini sama halnya dengan metode analitik pada umumnya yaitu berupa fungsi matematik yang berbentuk $u(x, t)$, dengan $x$ dan $t$ adalah konsentrasi polutan dalam posisi $x$ dan waktu $t$. Sehingga dengan mensubstitusi nilai pada $t$ akan diketahui nilai konsentrasi polutan yang ada pada aliran.

\section{KESIMPULAN}

Kesimpulan dari hasil penelitian :

1. Dalam membangun dan menganalisis persamaan transport, penulis memperoleh persamaan transport berdasarkan hukum kekekalan massa melalui formulasi integral.

2. Langkah-langkah dalam menentukan solusi umum dari persamaan transport $u_{t}+(c u)_{x}=$ 0 dengan metode Dekomposisi Adomian Laplace, yaitu :

a. Menerapkan Transformasi Laplace pada persamaan transport

b. Mensubstitusi nilai awal

c. Menyatakan solusi dalam bentuk deret tak hingga $u=\sum_{n=0}^{\infty} u_{n}$

d. Menggunakan Invers Transformasi Laplace

3. Solusi umum dari persamaan transport yang diperoleh pada penelitian ini adal

$$
\begin{aligned}
& u(x, t)=f(x)-c \frac{t}{1 !} \frac{\partial}{\partial x} u_{0}+c^{2} \frac{t^{2}}{2 !} \frac{\partial^{2}}{\partial x^{2}} u_{0}-c^{3} \frac{t^{3}}{3 !} \frac{\partial^{3}}{\partial x^{3}} u_{0}+c^{4} \frac{t^{4}}{4 !} \frac{\partial^{4}}{\partial x^{4}} u_{0}+ \\
& \ldots+(-1)^{n+1} c^{n+1} \frac{t^{n+1}}{(n+1) !} \frac{\partial^{(n+1)}}{\partial x^{(n+1)}} u_{0}
\end{aligned}
$$

\section{DAFTAR PUSTAKA}

Adawiyah, Robi'atul. 2016. Penyelesaian Persamaan Shock Wave Menggunakan Metode Dekomposisi Adomian Laplace. Skripsi. Fakultas Sains dan Teknologi Universitas Islam Negeri Maulana Malik Ibrahim.

Paskalia, Monica. 2018. Penyelesaian Numeris Persamaan Adveksi-Difusi Menggunakan Metode Beda Hingga. Skripsi. Fakultas Sains dan Teknologi Universitas Sanata Dharma Yogyakarta.

Setiawan, Ipung. 2011. Solusi Analitik Persamaan Transport dan Distribusi Anomiak. Skripsi. Fakultas Matematika dan Ilmu Pengetahuan Alam Universitas Diponegoro.

Side, Syafruddin. 2016. Persamaan Diferensial Parsial. Edisi 1. Universitas Negeri Makassar. Makassar. 
Stavroulakis, Ioannis P, Stepean A Tersian, Partial Differtial Equations, WorldScientific Publishing Co. Re. Ltd. 2004.

Wahidah.Wahyuni.dan Ratnasari.2015. Fungsi Green yang dikonstruksi pada Persamaan Diferensial Linear Tak Homogen Orde-n. Jurnal MSA . 3.1.

Wartono, Muhaijir. 2013. Penyelesaiaan Persamaan Riccati dengan menggunakan Metode Dekomposisi Adomian Laplace. Jurnal Sains, Teknologi, dan Industri. 10.2.

Yuni, Yulida. 2012. Metode Dekomposisi Adomian Laplace untuk Solusi Persamaan Diferensial Nonlinear Koefisien Fungsi. Jurnal Matematika Murni dan Terapan. 6(1): 17-26. 